\title{
Prediction of In-situ Strengths and Matrix Cracking in Composites under Transverse Tension and In-plane Shear
}

\author{
Pedro P. Camanho ${ }^{\text {a }}$, Carlos G. Dávila ${ }^{\mathrm{b}}$, Silvestre T. Pinho ${ }^{\mathrm{c}}$ \\ Lorenzo Iannucci ${ }^{\mathrm{c}}$, Paul Robinson ${ }^{\mathrm{c}}$ \\ ${ }^{a}$ DEMEGI, Faculdade de Engenharia, Universidade do Porto, Rua Dr. Roberto \\ Frias, 4200-465 Porto, Portugal \\ ${ }^{\mathrm{b}}$ NASA Langley Research Center, Hampton, VA 23666,U.S.A. \\ ${ }^{\mathrm{c}}$ Department of Aeronautics, Imperial College London, Prince Consort Road, \\ London SW7 2BY, U.K.
}

\begin{abstract}
A criterion for matrix failure of laminated composite plies in transverse tension and in-plane shear is developed by examining the mechanics of transverse matrix crack growth. Matrix cracks are assumed to initiate from manufacturing defects and can propagate within planes parallel to the fiber direction and normal to the ply midplane. Fracture mechanics models of cracks in unidirectional laminates, embedded plies and outer plies are used to determine the onset and direction of propagation of crack growth. The models for each ply configuration relate ply thickness and ply toughness to the corresponding in-situ ply strength. Calculated results for several materials are shown to correlate well with experimental results.
\end{abstract}

Key words: Failure criterion, In-situ strengths, Fracture. 


\section{INTRODUCTION}

Strength-based failure criteria are commonly used with the finite element method to predict failure events in composite structures. A large number of continuum-based criteria have been derived to relate stresses and experimental measures of material strength to the onset of failure. The most typical among the proposed criteria is Hashin's criterion [1] which assumes a quadratic interaction between the stresses acting on the fracture plane.

The recent World Wide Failure Exercise (WWFE) conceived and conducted by Hinton and Soden [1]-[6] provides a good assessment of the status of currently available theoretical methods for predicting material failure in fiber reinforced polymer composites. Comparison of the predictions by the WWFE participants with experimental results indicates that even when analyzing simple laminates that have been studied extensively over the past 40 years, the predictions of most theories differ significantly from the experimental observations.

One of the damage mechanims considered in the WWFE was transverse matrix cracking [1]-[6]. Transverse matrix cracking is often considered a benign mode of failure because it normally causes such a small reduction in the overall stiffness of a structure that it is difficult to detect during a test. However, transverse matrix cracks also provide the primary leakage path for gases in pressurized vessels. Leakage is a phenomenon that is receiving considerable interest after the cancelation of the NASA X-33 launch vehicle program [7], where it was found that liquid hydrogen had leaked at cryogenic temperatures and, once the temperature increased, caused major delaminations by 
cryopumping.

To predict matrix cracking in a laminate subjected to in-plane shear and transverse tensile stresses, a failure criterion should be established as a function of the "in-situ" strengths. The in-situ effect, originally detected in Parvizi's [8] tensile tests of cross-ply glass fiber reinforced plastics, is characterized by higher transverse tensile and shear strengths of a ply when it is constrained by plies with different fiber orientations in a laminate, compared with the strength of the same ply in a unidirectional laminate. The in-situ strength also depends on the number of plies clustered together, and on the fiber orientation of the constraining plies. The orientation of the constraining plies and the number of plies clustered together also affect the crack density and the stiffness reduction of the cracked ply. Experimental tests in $\left( \pm 25^{\circ} / 90_{n}^{\circ}\right)_{s}(\mathrm{n}=1,2,3)$ carbon/epoxy laminates have shown higher crack densities for thinner $90^{\circ}$ layers [9]. The reduction of the elastic properties of a cracked ply is normally predicted using elastic analyses of cracked plies [10]-[11], or Continuum Damage Models [12]$[15]$.

The in-situ effect is illustrated in Figure 1, where the relation between the insitu transverse tensile strength experimentally measured and the total number of $90^{\circ}$ plies clustered together $(2 \mathrm{n})$ is represented.

[Figure 1 about here]

It is clear that accurate in-situ strengths are necessary for any stress-based failure criterion for matrix cracking in constrained plies. Both experimental [9], [16]-[17] and analytical methods [10], [18] have been proposed to determine the in-situ strengths. Although the models proposed can satisfactory predict 
the in-situ transverse tensile strength, there is still the need to accurately predict the in-situ shear strength.

The uncertainty in the prediction of initiation and progression of damage in composites has led to the undertaking of an effort at the NASA Langley Research Center to revisit existing failure theories, assess their capabilities, and to develop new theories where necessary. As a result of that effort, a set of six criteria for predicting failure of unidirectional FRP laminates were proposed [19], [20].

The objectives of this paper are to present a detailed examination and validation of a novel failure criterion for matrix cracking under transverse tension combined with in-plane shear, and to develop a reliable model to predict the in-situ shear strength of laminated composites.

The in-situ transverse tensile and in-plane shear strengths, as well as the failure criterion for transverse tensile and in-plane shear acting simultaneously, follow from the respective critical energy release rate for crack propagation. The concept of interaction energy, which is defined as the energy released by the introduction of a crack in a ply subjected to in-plane transverse tensile and shear stresses, is used to calculate the individual components of the energy release rate. The in-situ strengths and failure criterion are obtained from the expressions of the components of the energy release rate. The accuracy of the model developed to predict in-situ strengths and of the failure criterion is assessed by comparing the predictions with published experimental data. 


\section{INTERACTION ENERGY AND ENERGY RELEASE RATE UNDER NON-LINEAR SHEAR BEHAVIOR}

\subsection{Background}

Laws [22] derived an expression for the interaction energy for a ply with an elliptical slit crack. The expression considers the combined action of transverse tensile and in-plane shear stresses, assuming a linear shear response [22]. It is considered here that the assumption of a linear in-plane shear behavior leads to an overprediction of the in-situ shear strength. Therefore, the generalization for a nonlinear shear behavior is developed. The procedure uses Eshelby's [23] application of the eigenstrain problem to solve the stress field around an elliptical crack, in a framework similar to the one proposed by Laws [22].

\subsubsection{The eigenstrain problem}

Consider an unstressed infinite solid that undergoes some physical process that generates inelastic strains. The physical process could for instance be plastic deformation or phase transformation. Probably due to the later, this inelastic strain is commonly called transformation strain. The problem consists in determining the stress and strain fields due to the transformation strains.

The total strain tensor $\varepsilon$ is the sum of an elastic strain tensor $\varepsilon^{e l}$ with the transformation strain tensor $\varepsilon^{t}$ :

$$
\varepsilon=\varepsilon^{e l}+\varepsilon^{t}
$$

and the stresses result from the elastic component of the strain: 


$$
\sigma=\mathbf{C}: \varepsilon^{e l}=\mathbf{C}:\left(\varepsilon-\varepsilon^{t}\right)
$$

where $\mathbf{C}$ is the constitutive tensor. Neglecting the body forces, the equilibrium equation is:

$$
\nabla \cdot \sigma=\mathbf{C}:\left(\nabla \cdot \varepsilon-\nabla \cdot \varepsilon^{t}\right)=\mathbf{0}
$$

or:

$$
\mathbf{C}: \nabla \cdot \varepsilon-\mathbf{b}^{t}=\mathbf{0}
$$

where $\mathbf{b}^{t}$ is a fictitious body force distribution defined as:

$$
\mathbf{b}^{t}=\mathbf{C}: \nabla \cdot \varepsilon^{t}
$$

If the transformation strains are known, then Equation (4) can be solved for $\varepsilon$ using Fourier transforms or Papkovich-Neuber potentials.

Consider the particular case of an elliptic volume $V$ bounded by a surface $S$ within an infinite body represented in Figure 2.

[Figure 2 about here]

The volume $V$ is described by the inequality:

$$
\left(\frac{x}{a}\right)^{2}+\left(\frac{y}{b}\right)^{2}+\left(\frac{z}{c}\right)^{2} \leq 1
$$


The elliptic region undergoes a change of form that without the constraint imposed by the surrounding material would result in an arbitrary homogeneous strain $\varepsilon^{t}$. The fictitious body forces defined by (5) are in this case zero everywhere except in the surface $S$ where they are:

$$
\mathbf{b}^{t}=\mathbf{C}: \varepsilon^{t} \delta\left(\left(\frac{x}{a}\right)^{2}+\left(\frac{y}{b}\right)^{2}+\left(\frac{z}{c}\right)^{2}-1\right) \cdot \mathbf{n}
$$

where $\mathbf{n}$ is the normal to the ellipsoid and $\delta(\cdot)$ the Dirac delta function.

Within the ellipsoid, the total strain field $\varepsilon=\varepsilon^{e l}+\varepsilon^{t}$ is uniform, and can be expressed as [22]:

$$
\varepsilon=\mathbf{P}: \mathbf{C}: \varepsilon^{t}
$$

where the fourth order tensor $\mathbf{P}$ results from solving (4) with $\mathbf{b}^{t}$ given by (7). $\mathbf{P}$ depends on the elastic properties of the material and geometry of the ellipsoid. The derivation of the tensor $\mathbf{P}$ can be found in references [24,25]. The stress field is then obtained as:

$$
\sigma=\mathbf{C}: \varepsilon^{e l}=\mathbf{C}:\left(\varepsilon-\varepsilon^{t}\right)=-(\mathbf{C}-\mathbf{C}: \mathbf{P}: \mathbf{C}): \varepsilon^{t}=-\mathbf{Q}: \varepsilon^{t}
$$

with:

$$
\mathbf{Q}=\mathbf{C}-\mathbf{C}: \mathbf{P}: \mathbf{C}
$$




\subsubsection{The Eshelby inhomegeneity problem}

Eshelby [23] showed that the eigenstrain problem can be used to determine the stress and strain fields that result from an elliptic inhomegeneity. Consider an elliptical inhomegeneity with a constitutive tensor $\mathbf{C}^{*}$ inside a homogeneous infinite solid with a constitutive tensor C. Supposing that the solid is loaded by an uniform stress or strain at infinity, $\sigma^{\infty}$ and $\varepsilon^{\infty}$ respectively, the stress and strain tensors can be expressed as:

$$
\sigma=\sigma^{\infty}+\tilde{\sigma} ; \quad \varepsilon=\varepsilon^{\infty}+\tilde{\varepsilon}
$$

where $\sigma^{\infty}$ and $\varepsilon^{\infty}$ are the uniform stress and strain tensors that would be induced in the solid if the inhomegeneity were not present, while $\tilde{\sigma}$ and $\tilde{\varepsilon}$ represent a perturbation due to the presence of the inhomegeneity.

The perturbation due to the inhomegeneity can be computed using the eigenstrain analogy. In fact, the stress field $\sigma=\sigma^{\infty}$ solves the equilibrium equations everywhere in the solid, except in the inclusion, where the error in the stress is uniform and equal to $\left(\mathbf{C}^{*}-\mathbf{C}\right): \varepsilon^{\infty}$. This suggests that the stress state can be corrected by using a transformation strain inside the inclusion. For the inhomegeneity and the transformed region to be equivalent, the stresses in both cases must be the same. For the case of the hypothetical transformed region, the stress is:

$$
\sigma=\mathbf{C}: \varepsilon^{e l}=\mathbf{C}:\left(\varepsilon-\varepsilon^{t}\right)
$$

while in the case of the inhomegeneity, the stress tensor is: 


$$
\sigma=\mathbf{C}^{*}: \varepsilon
$$

For the transformed region to be equivalent to the inhomegeneity, it follows from equations (12) and (13) that:

$$
\mathbf{C}:\left(\varepsilon-\varepsilon^{t}\right)=\mathbf{C}^{*}: \varepsilon
$$

Decomposing the strain $\varepsilon$ into its two components $\varepsilon^{\infty}$ and $\tilde{\varepsilon}$ in equation (14) gives:

$$
\mathbf{C}:\left(\varepsilon^{\infty}+\tilde{\varepsilon}-\varepsilon^{t}\right)=\mathbf{C}^{*}:\left(\varepsilon^{\infty}+\tilde{\varepsilon}\right)
$$

Expressing the perturbation strain $\tilde{\varepsilon}$ in terms of the transformation strain using equation (8), and replacing in equation (15):

$$
\mathbf{C}:\left(\varepsilon^{\infty}+\mathbf{P}: \mathbf{C}: \varepsilon^{t}-\varepsilon^{t}\right)=\mathbf{C}^{*}:\left(\varepsilon^{\infty}+\mathbf{P}: \mathbf{C}: \varepsilon^{t}\right)
$$

which can be re-arranged to:

$$
\left(\mathbf{C}-\mathbf{C}^{*}\right): \varepsilon^{\infty}=\left[\mathbf{C}-\left(\mathbf{C}-\mathbf{C}^{*}\right): \mathbf{P}: \mathbf{C}\right]: \varepsilon^{t}
$$

For a void, $\mathbf{C}^{*}=0$ and equation (17) reduces to:

$$
\varepsilon^{t}=\mathbf{Q}^{-1}: \sigma^{\infty}
$$

The determination of $\varepsilon^{t}$ in equation (18) is an important result since the strain and stress at the cavity wall follow as:

$$
\begin{aligned}
& \varepsilon=\varepsilon^{\infty}+\tilde{\varepsilon}=\varepsilon^{\infty}+\mathbf{P}: \mathbf{C}: \varepsilon^{t}=\varepsilon^{\infty}+\mathbf{P}: \mathbf{C}: \mathbf{Q}^{-1}: \sigma^{\infty} \\
& \sigma=\mathbf{C}: \varepsilon
\end{aligned}
$$


The interaction energy, defined as the energy released by the introduction of a crack when the solid is being loaded at infinity by the stress $\sigma^{\infty}$, was calculated for a linear-elastic material by Eshelby [23]. For a general constitutive model, the interaction energy is expressed as:

$$
E_{\text {int }}=\int_{V}\left[\int_{0}^{\varepsilon^{t}} \sigma^{\infty}: d \varepsilon^{t}\right] d V=V \int_{0}^{\varepsilon^{t}} \sigma^{\infty}: d \varepsilon^{t}
$$

where $V$ is the volume of the cavity. The derivation of equation (21) requires the use of equation (18) relating $\varepsilon^{t}$ to $\sigma^{\infty}$.

The definition of $\mathbf{Q}$ in equation (18) is not strictly valid for a non-linear material behavior, because the superposition principle is used in its derivation. As a result, there is an approximation implied in the use of equation (21) for a non-linear material behavior.

The solution for the interaction energy for a slit crack was obtained from the solution for an ellipsoidal cavity by Laws [22]. Laws considered first an infinite elliptic cylinder by taking $c \rightarrow \infty$, and by expressing the interaction energy per unit length of the cylinder as:

$$
E_{\text {int }}=\pi a_{0}^{2} \epsilon \int_{0}^{\varepsilon^{t}} \sigma^{\infty}: d \varepsilon^{t}, \quad \text { with } \epsilon=\frac{b}{a_{0}}
$$

A slit crack is represented by making $\epsilon \rightarrow 0$. Since the tensor $\mathbf{Q}$ becomes singular when $\epsilon \rightarrow 0$, but the product $\epsilon \mathbf{Q}^{-1}$ does not, some care has to be taken. Equation (22) can be transformed into: 


$$
E_{\text {int }}=\pi a_{0}^{2} \int_{0}^{\sigma^{\infty}} \sigma^{\infty}: \epsilon \mathbf{Q}^{-1}: d \sigma^{\infty}
$$

Making $\epsilon \rightarrow 0$, and defining $\boldsymbol{\Lambda}=\epsilon \mathbf{Q}^{-1}$, the interaction energy can be expressed as:

$$
E_{\text {int }}=\pi a_{0}^{2} \int_{0}^{\sigma^{\infty}} \sigma^{\infty}: \Lambda: d \sigma^{\infty}
$$

The tensor $\boldsymbol{\Lambda}$ depends on the tensor $\mathbf{P}$ (through the tensor $\mathbf{Q}$ ), which was obtained in an integral form in References [24,25]. The integral expression resulting for the tensor $\boldsymbol{\Lambda}$ cannot be exactly integrated. Laws [22] carried an approximate integration for a linear elastic material. Using Laws model [22] for a non-linear material behavior in shear implies a further approximation because the superposition principle was used to derive the tensor Q. However, the error in the predicted in-situ shear strength can be attributed to the assumption of linear shear response.

In fact, experimental results obtained in unidirectional composite materials subjected to in-plane shear stresses show a non-linear response, as illustrated in Figure 3.

[Figure 3 about here]

Figure 3 represents two major effects of the shear response of a composite material. Firstly, the shear modulus of the material is reduced in the unloadingloading cycles occurring after the onset of non-linearity, i.e., $\mathrm{G}_{12}^{(2)}<\mathrm{G}_{12}^{(1)}$. The reduction of the shear modulus is a result of the presence of damage in the 
material. The damage mechanisms are microcracks with sizes of the magnitude of the fibre diameter occurring in the matrix and at the fibre-matrix interface [26]-[27]. The premature growth of the micro-cracks to a macroscopic transverse cracks is prevented by the fibres [26].

The second effect is the presence of permanent shear deformations in the material, $\gamma_{12}^{\mathrm{p}}$. The permanent shear deformations are normally attributed to plastic or viscoplastic deformations in the matrix [28].

Based on these experimental observations, a modification to Laws model [22], assuming a non-linear shear behavior and plane stress, is proposed. Assuming a general shear behavior, equation (24) is written as:

$$
\begin{gathered}
E_{\text {int }}=\frac{1}{2} \pi a_{0}^{2}\left(\Lambda_{22}^{o} \sigma_{22}^{2}+2 \int_{0}^{\sigma_{12}} \sigma_{12} \Lambda_{12}^{o} d \sigma_{12}\right) \\
=\frac{1}{2} \pi a_{0}^{2}\left(\Lambda_{22}^{o} \sigma_{22}^{2}+2 \int_{0}^{\gamma_{12}} \sigma_{12} d \gamma_{12}\right) \\
=\frac{1}{2} \pi a_{0}^{2}\left[\Lambda_{22}^{o} \sigma_{22}^{2}+\chi\left(\gamma_{12}\right)\right]
\end{gathered}
$$

where $\chi\left(\gamma_{12}\right)$ is defined as:

$$
\chi\left(\gamma_{12}\right)=2 \int_{0}^{\gamma_{12}} \sigma_{12} d \gamma_{12}
$$

and $\Lambda_{22}^{o}$ is given by [18]:

$$
\Lambda_{22}^{o}=2\left(\frac{1}{E_{2}}-\frac{\nu_{21}^{2}}{E_{1}}\right)
$$

For a linear shear behavior Equation (25) reverts to the model proposed by Laws [22]. 


\section{SLIT CRACK MODEL AND ENERGY RELEASE RATES}

The failure criterion for predicting matrix cracking in a ply subjected to inplane shear and transverse tension and the expression to determine the in-situ strengths proposed are based on the Fracture Mechanics analysis of a slit crack in an unidirectional ply, as proposed by Dvorak and Laws [18]. The slit crack is lying on the 1-3 plane, as represented in Figure 4.

[Figure 4 about here]

The crack has a length $2 a_{0}$ along the thickness t of a ply. Physically, this crack represents a distribution of defects in the composite material: matrixfiber debonds, matrix voids, or clusters of densely packed fibers, corresponding to the preferential locus for void nucleation in the matrix [31].

The location and dimensions of matrix-fibre debonds or matrix voids are random variables that depend on the material and manufacturing process. The fibre distribution is also a random variable that defines the location of void nucleation in the matrix when the composite is subjected to transverse or shear stresses. The mechanistic and statistical representation of these damage mechanisms at the micromechanical level would be a formidable task, impractical for the purpose of designing a composite structure.

Therefore, it is assumed that the combination of these individual defects form an higher level of "effective cracks" [29]. Using the concept of effective crack the precise identities of the different micromechanical damage mechanisms are lost. However, the effects of the micromechanical damage mechanisms, i.e. the propagation of macrocracks along the transverse or longitudinal directions, re- 
sulting from the growth and interaction of the several micromechanical damage mechanisms, can be represented by the effective crack [30].

The effective slit crack represented in Figure 4, representing the macroscopic effect of defects that occur at the micromechanical level, can grow in the 1 (longitudinal, L) direction, in the 3 (transverse, $\mathrm{T}$ ) direction, or in both directions. Considering a non-linear shear behavior and neglecting the effects of the adjoining plies, the interaction energy is given by:

$$
E_{\text {int }}=\frac{1}{2} \pi a_{0}^{2}\left[\Lambda_{22}^{o} \sigma_{22}^{2}+\chi\left(\gamma_{12}\right)\right]
$$

Following Dvorak and Laws [18], the energy release rate for the case of crack propagation in the transverse direction is obtained as:

$$
G(T)=\frac{1}{2} \frac{\partial E_{i n t}}{\partial a_{o}}
$$

and for the longitudinal direction:

$$
G(L)=\frac{E_{\text {int }}}{2 a_{o}}
$$

Using (28) in (29)-(30), the mode I and mode II components of the energy release rate are obtained as:

$$
\begin{aligned}
G_{I}(T) & =\frac{\pi a_{o}}{2} \Lambda_{22}^{o} \sigma_{22}^{2} \\
G_{I I}(T) & =\frac{\pi a_{o}}{2} \chi\left(\gamma_{12}\right)
\end{aligned}
$$

for crack growth in the transverse direction, and: 


$$
\begin{aligned}
G_{I}(L) & =\frac{\pi a_{o}}{4} \Lambda_{22}^{o} \sigma_{22}^{2} \\
G_{I I}(L) & =\frac{\pi a_{o}}{4} \chi\left(\gamma_{12}\right)
\end{aligned}
$$

for crack growth in the longitudinal direction. The components of the energy release rate were defined in the previous equations as $G$, as usual in Linear Elastic Fracture Mechanics (LEFM). However, it should be noted that the mode II component of the energy release rate is obtained from a non-linear constitutive model. Under this circumstance the model II component of the energy release rate corresponds to the rate of decrease of potential energy with respect to crack length for fixed boundary conditions.

\section{DETERMINATION OF IN-SITU STRENGTHS}

Experimental observations have shown that the in-situ strengths of a ply in a laminate depend on its thickness [8]. In general, thinner plies have higher strengths than thicker ones (Figure 1). The in-situ strengths of a ply also depends upon its location in the laminate, i.e., if the ply is an embedded ply, constrained by another ply or group of plies, or if the ply is at the surface of the laminate (outer ply). The surfaces of outer plies are generally unconstrained so that surface cracks are likely to develop at those locations. The energy release rate is magnified due to the proximity of the slit crack to the surface of the laminate, thus lowering the in-situ strength.

Three ply configurations are considered for the determination of in-situ strengths: thick plies, thin plies, and thin outer plies. 


\subsection{Thick plies}

A thick ply embedded in a laminate is shown in Figure 5. The slit crack represented in Figure 5 propagates first in the transverse direction because the energy release rate is twice as large in the transverse direction as it is in the longitudinal direction, as can be observed by comparing equations (31) and (33). Therefore, the components of the energy release rate are given by equations (31)-(32).

[Figure 5 about here]

The in-situ tensile strength can be obtained by solving equation (31) for the stress at failure [18]:

$$
Y_{i s}^{T}=\sqrt{\frac{2 G_{I c}(T)}{\pi a_{0} \Lambda_{22}^{o}}}
$$

For a thick embedded ply loaded in mode II, the fracture toughness for crack propagation in the transverse direction is obtained from equations (26) and $(32)$ :

$$
G_{I I c}(T)=\pi a_{0} \int_{0}^{\gamma_{12}^{u}} \sigma_{12} d \gamma_{12}
$$

Hahn and Tsai proposed approximating the non-linear shear response with the following polynomial [33]:

$$
\gamma_{12}=\frac{1}{G_{12}} \sigma_{12}+\beta \sigma_{12}^{3}
$$


where $\beta$ defines the non-linearity of the shear stress-shear strain relation, which is zero for a linear behavior. Using the polynomial approximation (37), the mode II fracture toughness given by equation (36) becomes:

$$
G_{I I c}(T)=\pi a_{0}\left[\frac{\left(S_{L}^{i s}\right)^{2}}{2 G_{12}}+\frac{3}{4} \beta\left(S_{L}^{i s}\right)^{4}\right]
$$

Equations (35) and (38) can be used to calculate the in-situ transverse tensile strength and in-situ shear strength. Dvorak and Laws [18] observed that a unidirectional laminate can be considered to be a special case of a thick laminate in which the outer surfaces are unconstrained so that surface cracks can develop. This important observation allows the prediction of the in-situ strengths of thick plies using experimental data obtained for unidirectional laminates. Using the classical solutions for stress intensity factors of surface cracks in unidirectional laminates [32], the components of the fracture toughness are obtained as:

$$
\begin{aligned}
G_{I c}(T) & =1.12^{2} \pi a_{0} \Lambda_{22}^{o}\left(Y^{T}\right)^{2} \\
G_{I I c}(T) & =2 \pi a_{0} \int_{0}^{\gamma_{12}^{u}} \sigma_{12} d \gamma_{12}=2 \pi a_{0}\left[\frac{\left(S_{L}\right)^{2}}{2 G_{12}}+\frac{3}{4} \beta\left(S_{L}\right)^{4}\right]
\end{aligned}
$$

Using (35) and (39), the equation proposed by Dvorak and Laws [18] for the in-situ tensile strength is obtained:

$$
Y_{i s}^{T}=1.12 \sqrt{2} Y^{T}
$$

The in-situ shear strength, $S_{L}^{i s}$, is obtained from (38) and (40): 


$$
\frac{\left(S_{L}\right)^{2}}{G_{12}}+\frac{6}{4} \beta\left(S_{L}\right)^{4}=\frac{\left(S_{L}^{i s}\right)^{2}}{2 G_{12}}+\frac{3}{4} \beta\left(S_{L}^{i s}\right)^{4}
$$

Equation (42) has two imaginary roots and two real roots with opposite signs. The in-situ shear strength of a thick ply, $S_{L}^{i s}$, corresponds to the positive real root of (42).

\subsection{Thin plies}

The geometry of a thin embedded ply is represented in Figure 6. The slit crack represented in Figure 6 extends across the ply thickness and can only grow in the longitudinal direction. Therefore, the components of the energy release rate are given by equations (33) and (34).

[Figure 6 about here]

Considering pure mode I loading, the in-situ tensile strength of a thin embedded ply can be obtained from (33) as derived in Reference [18]:

$$
Y_{i s}^{T}=\sqrt{\frac{8 G_{I c}(L)}{\pi t \Lambda_{22}^{o}}}
$$

For a thin embedded ply loaded in mode II the fracture toughness is obtained as:

$$
G_{I I c}(L)=\frac{\pi t}{4} \int_{0}^{\gamma_{12}^{u}} \sigma_{12} d \gamma_{12}
$$

Substituting equation (37) in (44) yields: 


$$
\frac{\left(S_{i s}^{L}\right)^{2}}{8 G_{12}}+\frac{3}{16} \beta\left(S_{i s}^{L}\right)^{4}=\frac{G_{I I c}(L)}{\pi t}
$$

The in-situ shear strength of a thin ply, $S_{i s}^{L}$, corresponds to the real root of equation (45).

\subsection{Thin outer plies}

A thin outer ply, represented in Figure 7, is considered as a special case of a thin laminate, where the energy release rate is magnified due to the proximity of the slit crack to the surface of the laminate.

[Figure 7 about here]

Under this circumstance, the corresponding fracture toughness is given by:

$$
G_{I I c}=\frac{\pi t}{2} \int_{0}^{\gamma_{12}^{u}} \sigma_{12} d \gamma_{12}
$$

From (37), the following expression is derived:

$$
\frac{\left(S_{o}^{L}\right)^{2}}{4 G_{12}}+\frac{3}{8} \beta\left(S_{o}^{L}\right)^{4}=\frac{G_{I I c}}{\pi t}
$$

The in-situ strength of an outer ply is obtained solving equation (47). 


\subsection{General expression for the in-situ shear strengths}

The positive, real solutions of equations (36), (45) and (47) have all the same general form:

$$
S_{i s}^{L}=\sqrt{\frac{\left(1+\beta \phi G_{12}^{2}\right)^{1 / 2}-1}{3 \beta G_{12}}}
$$

where the parameter $\phi$ is defined according to the configuration of a given ply:

$$
\begin{aligned}
\text { For a thick ply : } \phi & =\frac{12\left(S^{L}\right)^{2}}{G_{12}}+\frac{72}{4} \beta\left(S^{L}\right)^{4} \\
\text { For a thin ply : } \phi & =\frac{48 G_{I I c}}{\pi t} \\
\text { For an outer ply: } \phi & =\frac{24 G_{I I c}}{\pi t}
\end{aligned}
$$

The special case of a linear shear behavior is obtained when $\beta$ tends to zero. Therefore, the in-situ shear strength of thin plies for linear shear response can be obtained as:

$$
\begin{aligned}
& S_{i s}^{L}=\lim _{\beta \rightarrow 0} \sqrt{\frac{\left(1+\beta \phi G_{12}^{2}\right)^{1 / 2}-1}{3 \beta G_{12}}}=\sqrt{\frac{\phi G_{12}}{6}} \therefore \\
& S_{i s}^{L}=\left\{\begin{array}{l}
\sqrt{\frac{8 G_{12} G_{I I c}}{\pi t}}, \text { thin embedded ply. } \\
2 \sqrt{\frac{G_{12} G_{I I c}}{\pi t}}, \text { thin outer ply. }
\end{array}\right.
\end{aligned}
$$

For thick embedded plies, the in-situ shear strength obtained for linear shear response is:

$$
S_{i s}^{L}=\lim _{\beta \rightarrow 0} \sqrt{\frac{\left(1+\beta \phi G_{12}^{2}\right)^{1 / 2}-1}{3 \beta G_{12}}}=\sqrt{2} S^{L}
$$


Equations (50) and (51) are equal to the ones obtained by Dvorak and Laws [18] and Dávila and Camanho [19], [20] for linear shear behavior. The comparison between the predictions of the in-situ shear strength of T300/BSL 914C CFRP [16], assuming $\beta=3.6 \times 10^{-8} \mathrm{MPa}^{-3}$ and using linear and non-linear shear stress-shear strain relations, is shown in Figures 8 and 9, for the cases of a thin embedded ply and a thin surface ply, respectively.

[Figure 8 about here]

[Figure 9 about here]

It can be seen that there is a significant difference in the predicted in-situ strengths with linear or non-linear shear response. For example, the predicted in-situ shear strength of one embedded ply assuming linear behavior is 2.1 times higher than the predicted in-situ shear strength assuming non-linear behavior.

\section{FAILURE CRITERIA FOR TRANSVERSE TENSION AND IN-PLANE SHEAR}

In $\mathrm{Wu}$ and Reuter's experiments [34] composite specimens were tested under pure mode I, pure mode II, and mixed-mode I and II loading. Based on the experimental data obtained by $\mathrm{Wu}$ and Reuter [34], Hahn [35] proposed a mixed mode criterion written as a polynomial in the stress intensity factors $K_{I}$ and $K_{I I}$ : 


$$
(1-g) \frac{K_{I}}{K_{I c}}+g\left(\frac{K_{I}}{K_{I c}}\right)^{2}+\left(\frac{K_{I I}}{K_{I I c}}\right)^{2} \leq 1
$$

with $g=\frac{G_{I c}}{G_{I I c}}$. Using Linear-Elastic Fracture Mechanics, assuming self-similar crack growth, and taking into account that the crack is oriented along one of the principal directions of elastic symmetry of an orthotropic ply, the stress intensity factors can be related to the components of the energy release rates as:

$$
\begin{gathered}
G_{I}=\frac{A}{\sqrt{2 E_{1} E_{2}}} K_{I}^{2} \\
G_{I I}=\frac{A}{\sqrt{2} E_{1}} K_{I I}^{2}
\end{gathered}
$$

with $A=\sqrt{\left(\frac{E_{1}}{E_{2}}\right)^{1 / 2}-v_{21}+\frac{E_{1}}{2 G_{12}}}$. Using (53) and (54) in (52), the Hahn criterion becomes:

$$
(1-g) \sqrt{\frac{G_{I}}{G_{I c}}}+g \frac{G_{I}}{G_{I c}}+\frac{G_{I I}}{G_{I I c}} \leq 1
$$

Using equations (33)-(34) or (31)-(32) for a linear shear stress-shear strain response in (55), the failure criterion proposed by Dávila and Camanho [19][21] is obtained:

$$
(1-g) \frac{\sigma_{22}}{Y_{i s}^{T}}+g\left(\frac{\sigma_{22}}{Y_{i s}^{T}}\right)^{2}+\left(\frac{\sigma_{12}}{S_{i s}^{L}}\right)^{2} \leq 1
$$

For a non-linear shear behavior, the last term in (56) must be modified because Equation (54) is valid for linear constitutive models only. Sandhu [36], assuming a non-linear elastic behavior, proposed the use of the strain energy 
density for the prediction of failure in materials exhibiting non-linear behavior. For a non-linear shear behavior, the last term of Equation (56) is modified using the contribution of the shear stress and shear strain to the strain energy density as:

$$
(1-g) \frac{\sigma_{22}}{Y_{i s}^{T}}+g\left(\frac{\sigma_{22}}{Y_{i s}^{T}}\right)^{2}+\frac{\chi\left(\gamma_{12}\right)}{\chi\left(\gamma_{12}^{u}\right)} \leq 1
$$

Equation (57) represents the general form of the failure criterion for predicting matrix cracking under transverse tension and in-plane shear. Equations (56) and (57) are equivalent when the relation between the shear stress and the shear strain is linear.

The function $\chi\left(\gamma_{12}\right)$ can be defined knowing the non-linear shear behavior, $\sigma_{12}=\sigma_{12}\left(\gamma_{12}\right)$. However, for a multidirectional laminate, it is clear that the shape of the non-linear shear stress-shear strain relation depends on the transverse stresses. The non-linearity in the shear response is mostly a result of damage mechanisms involving the growth and coalescence of microcracks in the matrix [26]. It is therefore reasonable to expect that the onset and growth of the microcracks are affected by the presence of transverse stresses.

The effect of the transverse stresses on the non-linear shear stress-shear strain relation is clearly shown in Puck's experimental results [26], illustrated schematically in Figure 10.

[Figure 10 about here]

Therefore, the term $\chi\left(\gamma_{12}\right)$ in equation (57) should be computed from a constitutive model capable of representing the effect of the transverse tensile stress 
on the shear stress-shear strain relation.

\section{COMPARISON BETWEEN PREDICTIONS AND EXPERI- MENTAL RESULTS}

\subsection{In-situ shear strengths}

The in-situ transverse tensile strengths for thick and thin plies that are predicted using equations (41) and (43), respectively, have been found to correlate well with experimental results, as reported in Ref. [18]. However, there is still the need to validate the models proposed to predict the in-situ shear strengths.

Experimental results for CFRP laminates by Chang et al. [16] are used here to assess the accuracy of the equation proposed to predict the in-situ shear strengths, equation (48). Chang and Chen tested CFRP laminates with different lay-ups using the 2-rail shear test method and reported the values of the in-situ shear strengths as a function of the number of plies clustered together. The material tested was a T300/1034 CFRP, whose mechanical properties were measured by Chang and Chen [16] and Shahid and Chang [11]. The material properties are shown in Tables 1 and 2 .

[Table 1 about here]

[Table 2 about here]

The lay-up considered was $\left(0_{\mathrm{n}}^{\circ} / 90_{\mathrm{n}}^{\circ}\right)_{\mathrm{S}}, \mathrm{n}=1, \ldots 6$, and the experimental in-situ strengths as a function of the number of plies measured by Chang and Chen 
[16] are presented in Figure 11.

[Figure 11 about here]

The results shown in Figure 11 demonstrate the reduction of the in-situ shear strength that results from stacking together plies with the same orientation. The in-situ strength of a laminate composed of $\left(0^{\circ} / 90^{\circ}\right)$ sublaminates is twice as high as that of a laminate composed of $\left(0_{6}^{\circ} / 90_{6}^{\circ}\right)$ sublaminates. In fact, the results obtained for $n=6$ is surprising because an in-situ shear strength $20 \%$ lower than the one obtained in an unidirectional laminate was measured. The reason for this apparent inconsistency is that the experimental results must be corrected to account for the presence of residual thermal stresses. As a result of the difference between curing and room temperatures and the resulting orthotropic thermal contractions of the plies, tensile stresses develop in the fiber direction and compressive stresses develop in the direction normal to the fibers. The plies are therefore subjected to a multiaxial stress state and a failure criterion should be used to correct the in-situ strengths measured in the experiments.

In order to correct the predicted in-situ strengths the following typical values for CFRP coefficients of thermal expansion are assumed: $\alpha_{11}=-1 \times 10^{-6} /{ }^{\circ} \mathrm{C}$ and $\alpha_{22}=26 \times 10^{-6} /{ }^{\circ} \mathrm{C}$. For a temperature difference of $-125^{\circ} \mathrm{C}$, the transverse tensile stress calculated using classical lamination theory is $\sigma_{22}^{\Delta T}=$ 29.3MPa in all plies of the laminate.

The prediction of the in-situ strength with Equations (48) and (49) depends on the shear nonlinearity parameter $\beta$. In the following calculations, it is assumed that $\beta$ is the same for the laminate under investigation as for a 
unidirectional laminate of the same material system. Therefore, the values of $\beta$ used in the following laminate shear strength predictions were calculated by fitting Hahn's polynomial shear function (37) to published stress-strain data for unidirectional laminates. The results of least-squares approximations of test data for T300/BSL 914C [3] and T300/976 [37] are shown in Table 3.

[Table 3 about here]

After calculating the residual thermal stresses and the parameter $\beta$, it is possible to correct the experimental data and compute the in-situ shear strengths by taking into account the residual thermal stresses. The in-situ shear strength $S_{i s}^{L}$ is obtained by solving the failure criterion proposed in equation (57). For convenience, the term $\psi$ is defined as:

$$
\psi=(1-g) \frac{\sigma_{22}^{\Delta T}}{Y_{i s}^{T}}+g\left(\frac{\sigma_{22}^{\Delta T}}{Y_{i s}^{T}}\right)^{2}-1
$$

where the tensile strength $Y_{i s}^{T}$ is calculated using equation (43). The effective experimental in-situ shear strength, corrected for residual thermal stresses, is given by the positive real root of equation (57), which is:

$$
S_{i s}^{L}=-\frac{\sqrt{-3 \beta \mathrm{G}_{12} \psi\left(\psi+\sqrt{-\psi\left(-\psi+9 \beta^{2} \mathrm{G}_{12}^{2} \sigma_{12}^{4}+6 \beta \sigma_{12}^{2} \mathrm{G}_{12}\right)}\right)}}{3 \beta \mathrm{G}_{12} \psi}
$$

The laminate under investigation, $\left(0_{\mathrm{n}}^{\circ} / 90_{\mathrm{n}}^{\circ}\right)_{\mathrm{S}}$, contains an outer ply with a total thickness corresponding to half of the thickness of the embedded ply. Using equations (48) and (49) it can be concluded that the in-situ strength 
of the outer and embedded plies are the same, and matrix cracking occurs simultaneously in all the plies of the laminate.

The experimental results of Chang et al. [16] and the corresponding predicted shear strengths are compared in Figure 12 for two values of the shear nonlinearity parameter $\beta$. The predictions of the linear model are obtained using equations (50), whereas the predictions of the non-linear model are obtained using equation (48).

[Figure 12 about here]

An excellent agreement between the proposed non-linear model and experimental results is obtained for the two values of $\beta$ used. It can be observed that the linear shear strain model significantly overpredicts the in-situ shear strength. For $\beta=2.44 \times 10^{-8} \mathrm{MPa}^{-3}$ and $\mathrm{n}=1$, the errors in the predicted shear strengths using the linear and the non-linear equations are $95.5 \%$ and $-3.6 \%$, respectively.

\subsection{Failure envelopes}

The failure criteria proposed in equations (56) and (57) are used to predict the failure envelopes in the $\left(\sigma_{22}, \sigma_{12}\right)$ space, with $\sigma_{22} \geq 0$, for carbon and glassfiber reinforced composite materials. The results are compared with published experimental data for AS4-55A (Swanson et al. [38]), E-Glass-LY556 (Hinton et al. [3]), and Scotch-Ply Type 1002 (Voloshin et al. [39]). The corresponding elastic properties and strengths are shown in Table 4. 
[Table 4 about here]

There is no experimental information concerning the relation between the nonlinear shear behavior and the applied transverse tensile stresses. Furthermore, for AS4-55A and Scotch-Ply Type 1002, the shear stress-shear strain relation is not provided, even for unidirectional test specimens. Therefore, it is not possible to define the function $\chi\left(\gamma_{12}\right)$ for the materials under investigation, and the linear form of the failure criterion proposed, equation (56), is used to predict the failure envelopes for the AS4-55A and Scotch-Ply Type 1002 materials.

The lamina strengths predicted using the maximum stress criterion, the Hashin criterion, and the present criterion given by equation (56) are compared in Figure 13 for a carbon fiber material system and in Figure 14 and 15 for a glass fiber material system.

[Figure 13 about here]

[Figure 14 about here]

It can be observed that the strengths calculated with the present criteria correlate well with the experimental results. Furthermore, the results obtained with the criteria proposed represent an improvement over the commonly used Hashin and maximum stress failure criteria for the loading cases and range of materials investigated.

The shear stress-shear strain relation of the E-Glass-LY556 composite material is presented in Ref. [3]. For this material, the parameter $\beta$, which defines 
the shear response when the material is subjected to in-plane shear stresses, is calculated as $\beta=4.62 \times 10^{-8} \mathrm{MPa}^{-3}$. The accurate definition of the function $\chi\left(\gamma_{12}\right)$ when the material is under the combined effect of in-plane shear stresses and transverse tensile stresses would require a constitutive model based on continuum damage mechanics. Such models are able to represent the onset and growth of the non-critical damage mechanisms that contribute to the non-linear response represented in Figure 3. Continuum damage models incorporate damage onset and damage evolution equations that are functions of the relevant components of the stress tensor. Therefore, the effects of the transverse stress on the shear response can be taken into account.

In the absence of a constitutive model able to define the function $\chi\left(\gamma_{12}\right)$ under multiaxial loading, the criterion based on a non-linear shear response proposed, equation (57), can be used to predict the strength E-Glass-LY556 using two simplifying models.

In the first model it is assumed that the material shear response is non-linear elastic and independent of the transverse stresses (i.e. $\beta$ is constant). Under these circumstances, it is possible to predict the lamina strength using (37) and the failure criterion proposed in equation (57). The resulting failure criterion is:

$$
(1-g) \frac{\sigma_{22}}{Y_{i s}^{T}}+g\left(\frac{\sigma_{22}}{Y_{i s}^{T}}\right)^{2}+\frac{\frac{\sigma_{12}^{2}}{G_{12}}+\frac{3}{2} \beta \sigma_{12}^{4}}{\frac{\left(S_{i s}^{L}\right)^{2}}{G_{12}}+\frac{3}{2} \beta\left(S_{i s}^{L}\right)^{4}} \leq 1
$$

The second model assumes that the material shear response is non-linear elastic, and that $\beta$ depends linearly on the transverse tensile stress, $\sigma_{22}$, as: 


$$
\bar{\beta}\left(\sigma_{22}\right)=\beta_{0}+\frac{\sigma_{22}}{\kappa}
$$

where $\beta_{0}$ is the shear response factor for in-plane shear $\left(\beta_{0}=4.62 \times 10^{-8}\right.$ $\left.\mathrm{MPa}^{-3}\right)$. Assuming $\bar{\beta}\left(\sigma_{22}=30 \mathrm{MPa}\right)=2 \beta_{0}$ results in $\kappa=6.5 \times 10^{8} \mathrm{MPa}^{4}$. The corresponding shear responses for $\sigma_{22}=0 \mathrm{MPa}, \sigma_{22}=15 \mathrm{MPa}$ and $\sigma_{22}=$ $30 \mathrm{MPa}$ are represented in Figure 16.

[Figure 16 about here]

The lamina strengths predicted using the Hashin criterion and the present criteria given by equations (56) and (57) are compared in Figure 15 for EGlass-LY556 GFRP.

[Figure 15 about here]

The strengths calculated with the present criteria are in good agreement with the experimental results. The failure criteria based on equations (56) and (57), when accounting for the effect of the transverse stress on the shear response, provide the most accurate predictions. The experimental results obtained for E-glass LY556 when subjected to high values of transverse stress are sparse. In this region, Hashin's criterion and the criteria proposed here provided similar results. 


\section{CONCLUSIONS}

A new analytical closed-form model to predict the in-situ shear strength of composite laminates was proposed. Using a non-linear shear stress-shear strain constitutive behavior, the model proposed can accurately predict the in-situ shear strength as a function of ply thickness and ply location. The accurate values of the in-situ shear strength that can be obtained using the proposed model are essential for the prediction of matrix transverse cracking in multidirectional laminates.

Based on the calculation of mode I and mode II energy release rates, a new stress-based failure criterion for matrix cracking under in plane shear and transverse tension is proposed. The predictions of the criterion are compared with published experimental data for carbon- and glass-fiber reinforced composites. A good agreement between the experimental results and experimental data is obtained. Furthermore, the predictions of the failure criterion proposed indicate a better correlation with experimental data than Hashin and maximum stress criteria.

\section{Acknowledgements}

The financial support of the Portuguese Foundation for Science and Technology (FCT) under the project POCTI/EME/43525/2000, funded by POCTI and FEDER programmes, is acknowledged by the first author. 


\section{References}

[1] Hashin, Z. Failure criteria for unidirectional fiber composites. Journal of Applied Mechanics. 1980; 47:329-334.

[2] Hinton, M. J. and Soden, P. D. Predicting failure in composite laminates: the background to the exercise. Composites Science and Technology. 1998; 58:10011010.

[3] Soden, P. D.; Hinton, M. J., and Kaddour, A. S. Lamina properties, lay-up configurations and loading conditions for a range of fibre-reinforced composite laminates. Composites Science and Technology. 1998; 58:1011-1022.

[4] Hinton, M. J.; Kaddour, A. S., and Soden, P. D. A comparison of the predictive capabilities of current failure theories for composite laminates, judged against experimental evidence. Composites Science and Technology. 2002; 62:1725-1797.

[5] Soden, P. D.; Kaddour, A. S., and Hinton, M. J. Recommendations for designers and researchers resulting from the worl-wide failure exercise. Composites Science and Technology. 2004; 64:589-604.

[6] Soden, P. D.; Hinton, M. J., and Kaddour, A. S. A comparison of the predictive capabilities of current failure theories for composite laminates. Composites Science and Technology. 1998; 58:1225-1254.

[7] Rivers, H.K., Sikora, J.G., and Sankaran, S.N. Detection of micro-Leaks through complex geometries under mechanical load and at cryogenic temperature, Proceedings of the 42nd AIAA/ASME/ASCE/AHS/ASC Structures, Structural Dynamics and Materials Conference, Seattle, WA, April 16-19, 2001.

[8] Parvizi, A., Garrett, K., and Bailey J. Constrained cracking in glass fibrereinforced epoxy cross-ply laminates, Journal of Material Science, 13, 195-201, 
1978.

[9] Crossman, F. W., Warren, W. J., Wang, A. S. D., and Law Jr., G. E. Initiation and growth of transverse cracks and edge delamination in composite laminates part 2. experimantal results, Journal of Composite Materials. 1980; 14:88-108.

[10] Tan, S. C. and Nuismer, R. J. A theory for progressive matrix cracking in composite laminates. Journal of Composite Materials. 1989; 23:1029-1047.

[11] Shahid, I. S. and Chang, F. K. An accumulative damage model for tensile and shear failures of laminated composite plates. Journal of Composite Materials. $1995 ; 29: 926-981$.

[12] Talreja, R. Transverse cracking and stiffness reduction in composite laminates. Journal of Composite Materials. 1985; 19:355-375.

[13] Talreja, R., Yalvac, S., Yats, L. D., and Wetters, D. G. Transverse cracking and stiffness reduction in cross ply laminates of different matrix toughness. Journal of Composite Materials. 1992; 26(11):1644-1663

[14] Allen, D. H., Harris, C. E., and Groves, S. E. A thermomechanical constitutive theory for elastic composites with distributed damage- I. theoretical development. International Journal of Solids and Structures. 1987; 23(9):13011318.

[15] Allen, D. H., Harris, C. E., and Groves, S. E. A thermomechanical constitutive theory for elastic composites with distributed damage- II. application to matrix cracking in laminated composites. International Journal of Solids and Structures. 1987; 23(9):1319-1338.

[16] Chang, F. K. and Chen, M. H. The in-situ ply shear strength distributions in graphite/epoxy laminated composites. Journal of Composite Materials. 1987; 21:708-733. 
[17] Flaggs, D. L. and Kural, M. H. Experimental determination of the in situ transverse lamina strength in graphite/epoxy laminates. Journal of Composite Materials. 1982; 16:103-116.

[18] Dvorak, G. J. and Laws, N. Analysis of progressive matrix cracking in composite laminates II. first ply failure. Journal of Composite Materials. 1987; 21:309-329.

[19] Dávila, C. G. and Camanho, P. P. Failure Criteria for FRP Laminates in Plane Stress. NASA/TM-2003-212663. National Aeronautics and Space Administration; 2003.

[20] Dávila, C. G., Camanho P. P., and Rose, C. A. Failure criteria for FRP laminates, Journal of Composite Materials. 2004; 39:323-345.

[21] Pinho, S. T., Dávila, C. G., Camanho, P. P. Iannucci, L. and Robinson, P. Failure models and criteria for FRP under in-plane or three-dimensional stress states including shear non-linearity. NASA/TM-2005-213530. National Aeronautics and Space Administration; 2005.

[22] Laws, N. A note on interaction energies associated with cracks in anisotropic solids. Philosophical Magazine. 1977; 36(2):367-372.

[23] Eshelby, J. D. The determination of the elastic field of an ellipsoidal inclusion, and related problems. Proceedings of the Royal Society. 1957; A241:376-396.

[24] Kinoshita, K. and Mura, T. Elastic fields of inclusions in anisotropic media. Physics of State Solids (a). 1971; 5:759-768.

[25] Faivre, G. Hétérogénéités ellipsoïdales dans un milieu élastique anisotrope, Le Journal de Physique, 32, 325-331, 1971.

[26] Puck, A. and Schürmann, H. Failure analysis of FRP laminates by means of physically based phenomenological models. Composites Science and Technology. 1998; 58:1045-1067. 
[27] Varna, J., Joffe, R., Akshantala, N.V. and Talreja, R. Damage in compsite laminates with off-axis plies. Composites Science and Technology. 1999; 59:21392147.

[28] Ladevèze, P., Allix, O., Deü, J.-F. and Lévêque, D. A mesomodel for localisation and damage computation in laminates. Computer Methods in Applied Mechanics and Engineering. 2000; 183:105-122.

[29] Wisnom, M.R. Size effects in composites, in Comprehensive Composite Materials, A. Kelly and C. Zweben, eds., 2000; 5:23-48, Elsevier.

[30] Wang, A.S.D. Fracure mechanics of sublaminate cracks in composite materials. Composites Technology Review. 1984; 6:45-62.

[31] Mansilla, D.T., Analysis and simulation of transverse random fracture of long fibre reinforced composites, PhD Thesis, Universitat de Girona, Catalunya, Spain, 2005.

[32] Tada, H., Paris, P. C. and Irwin, G. R. The Stress Analysis of Cracks Handbook. American Society of Mechanical Engineers, New York, 2000.

[33] Hahn, H. T. and Tsai, S. W. Nonlinear elastic behaviour of unidirectional composite laminate. Journal of Composite Materials. 1973; 7:102-110.

[34] Wu, E. M. and Reuter Jr., R. C. Crack extension in fiberglass reinforced plastics. Department of Theoretical and Applied Mechanics, University of Illinois; 1965; T\&AM Report 275.

[35] Hahn, H. T. A mixed-mode fracture criterion for composite materials. Composites Technology Review. 1983;5:26-29.

[36] Sandhu, R. S. Nonlinear behavior of unidirectional and angle ply laminates. Journal of Aircraft. 1976; 13(2):104-111. 
[37] Chang, F. K., and Lessard, L. B. Damage tolerance of laminated composites containing an open hole and subjected to compressive loadings: Part I-Analysis, Journal of Composite Materials. 1991; 25:2-43.

[38] Swanson, S. R., Messick, M. J. and Tian, Z. Failure of carbon epoxy lamina under combined stresses, Journal of Composite Materials. 1987; 21: 619-630.

[39] Voloshin. A. and Arcan, M., Failure of unidirectional fiber-reinforced materialsnew methodology and results. Experimental Mechanics, 1980; 20: 280-284. 


\section{List of Figures}

1 In-situ effect in laminated composites (after Dvorak [18]).

40

2 Elliptic volume $\mathrm{V}$ representing an inhomogeneity within an infinite body.

3 Schematic representation of the non-linear shear response.

$4 \quad$ Slit crack geometry (after Dvorak [18]).

5 Thick embedded ply.

6 Thin embedded ply.

$7 \quad$ Thin outer ply.

8 Linear and non-linear predictions for the in-situ shear strength of a thin embedded ply.

9 Linear and non-linear predictions for the in-situ shear strength of a thin surface ply.

10 Effect of transverse normal stress in the shear stress-shear strain relation (after Puck [26]).

11 Experimental results: in-situ and unidirectional shear strengths.

12 Comparison between model predictions and experimental data. 
13 Comparison between model predictions and experimental data- AS4-55A.

14 Comparison between model predictions and experimental data-Scotch-Ply.

15 Shear stress-shear strain relations for $\beta=\beta\left(\sigma_{22}\right)$.

16 Comparison between model predictions and experimental data-E-Glass-LY556. 


\section{List of Tables}

$1 \quad$ T300/1034-C elastic properties. 48

2 T300/1034-C properties. 48

$3 \quad$ Shear nonlinearity parameter $\beta$ for two CFRP material systems.

$4 \quad$ Elastic properties and strengths. 


\section{Figures}

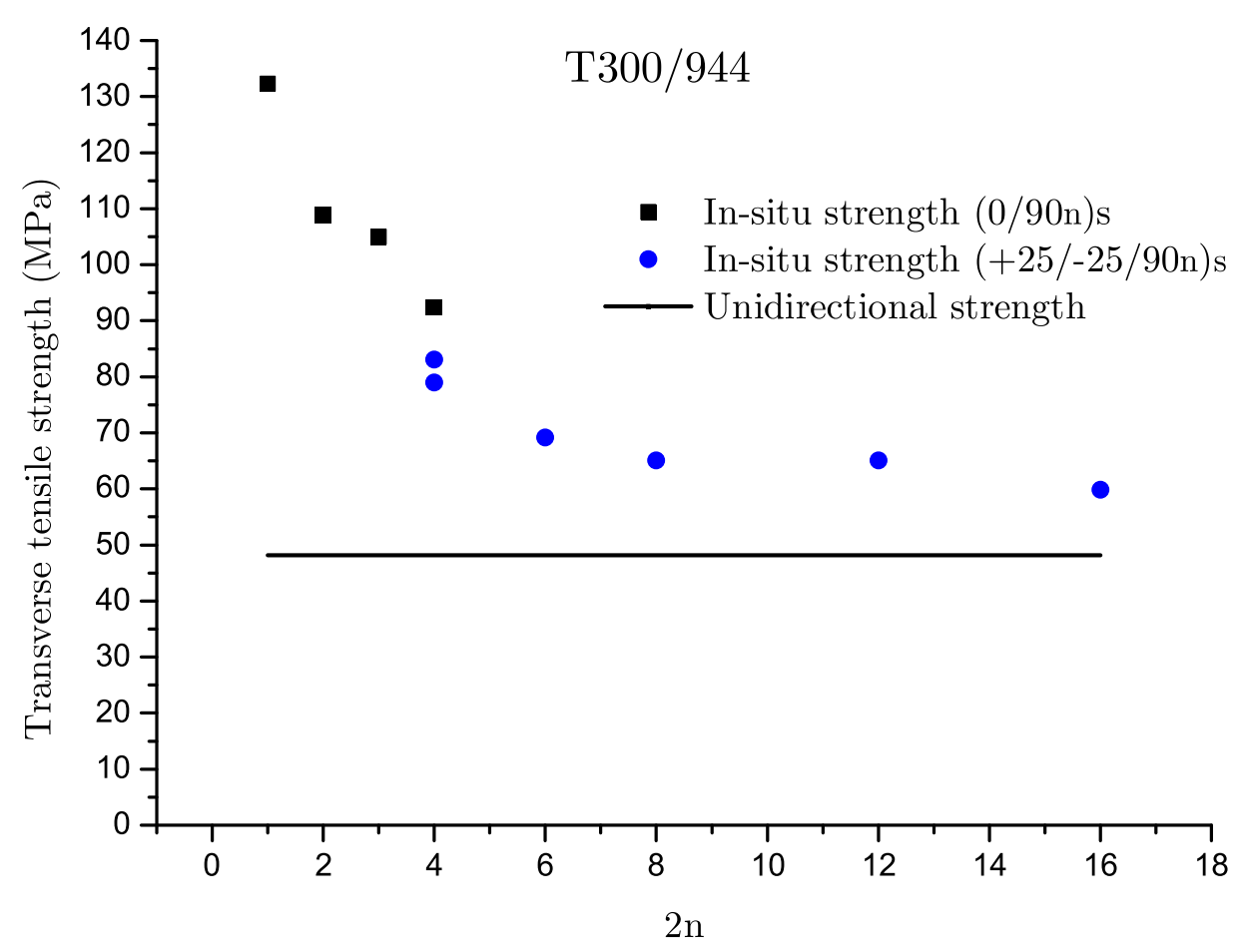

Fig. 1. In-situ effect in laminated composites (after Dvorak [18]).

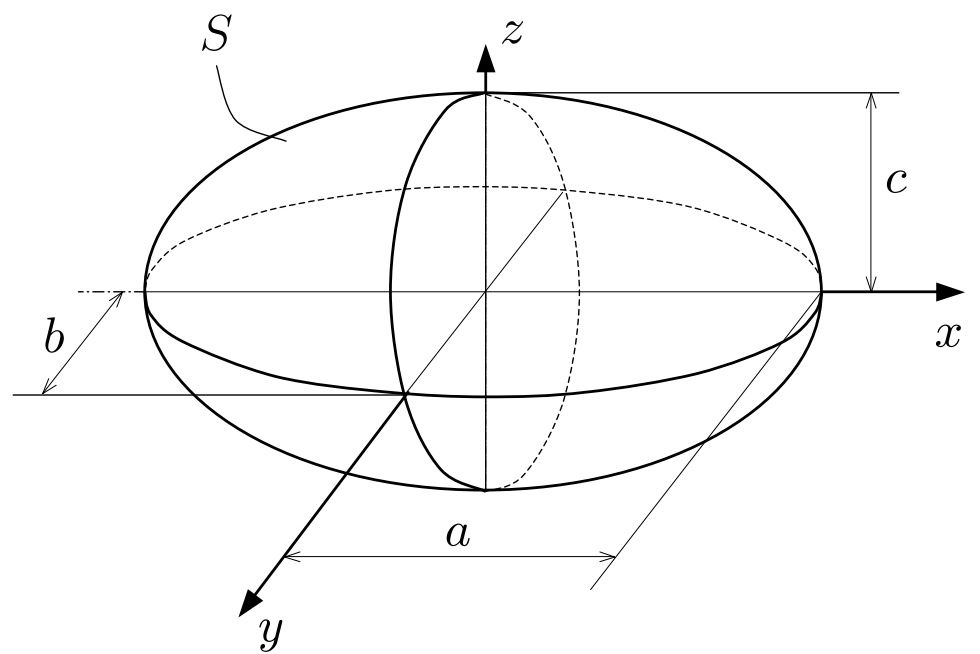

Fig. 2. Elliptic volume V representing an inhomogeneity within an infinite body. 


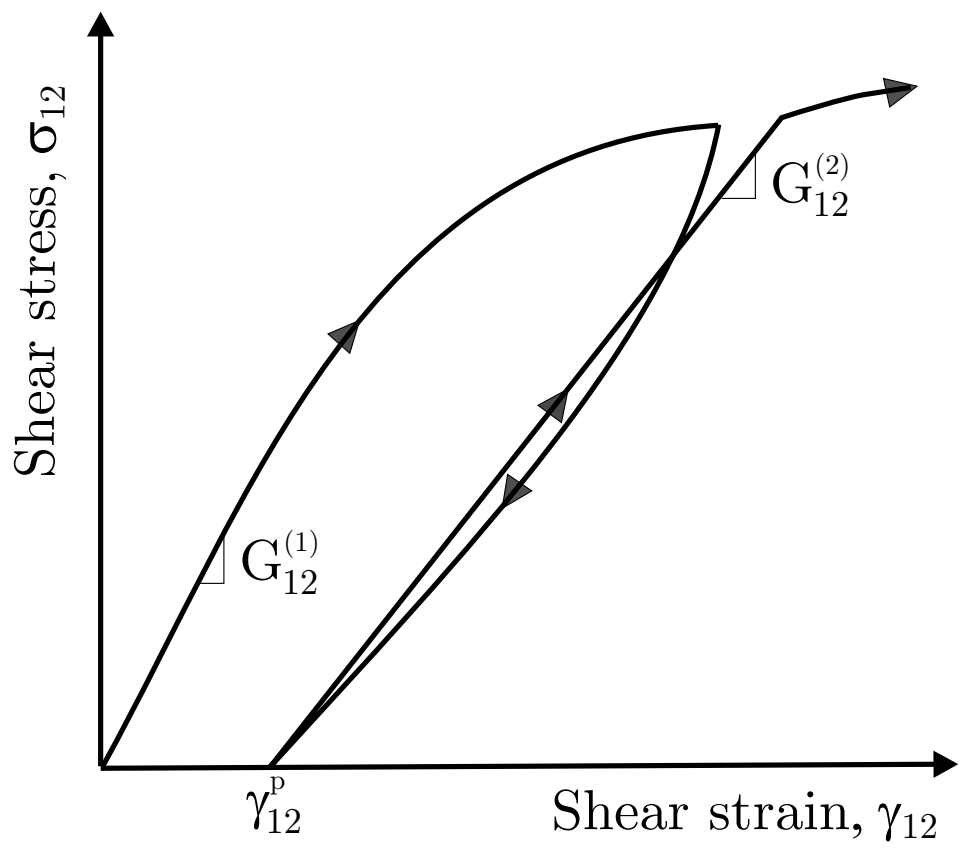

Fig. 3. Schematic representation of the non-linear shear response.
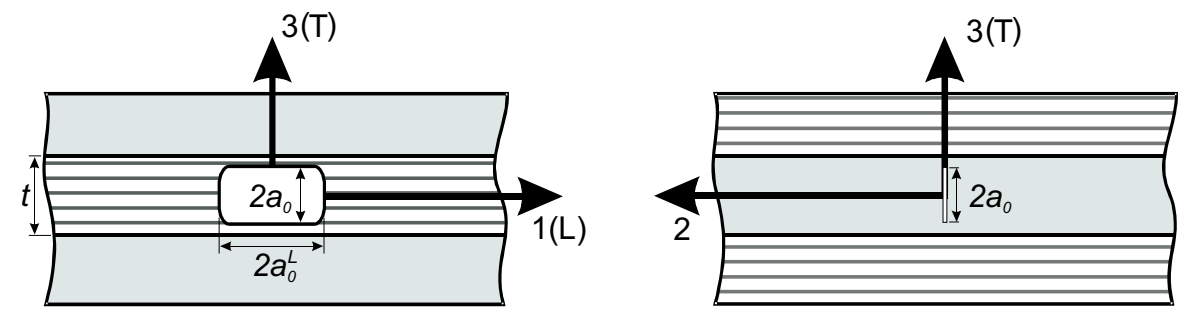

Fig. 4. Slit crack geometry (after Dvorak [18]). 


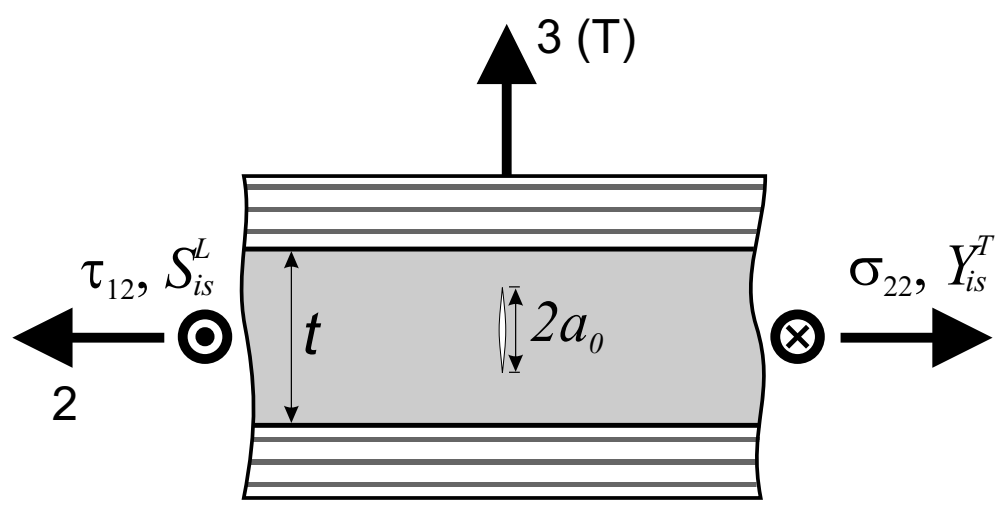

Fig. 5. Thick embedded ply.

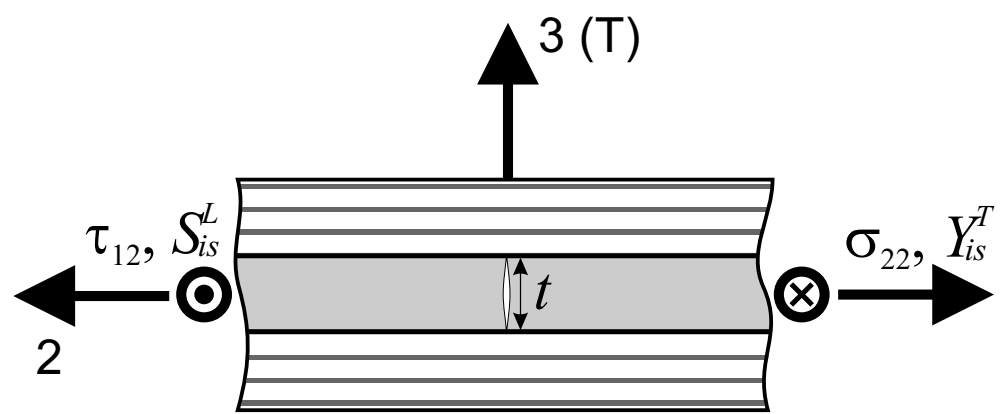

Fig. 6. Thin embedded ply. 


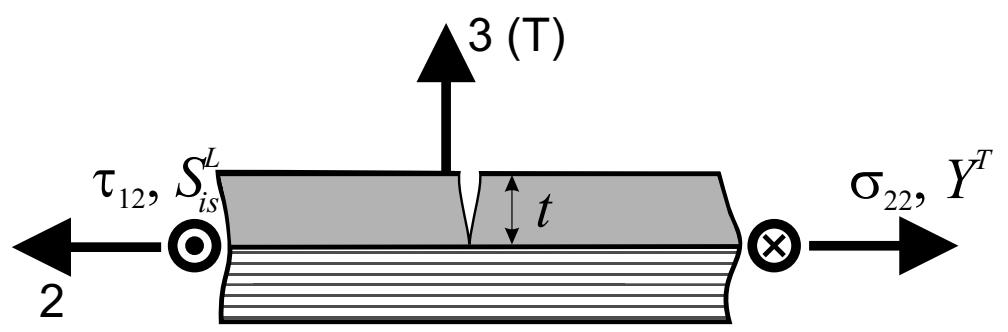

Fig. 7. Thin outer ply.

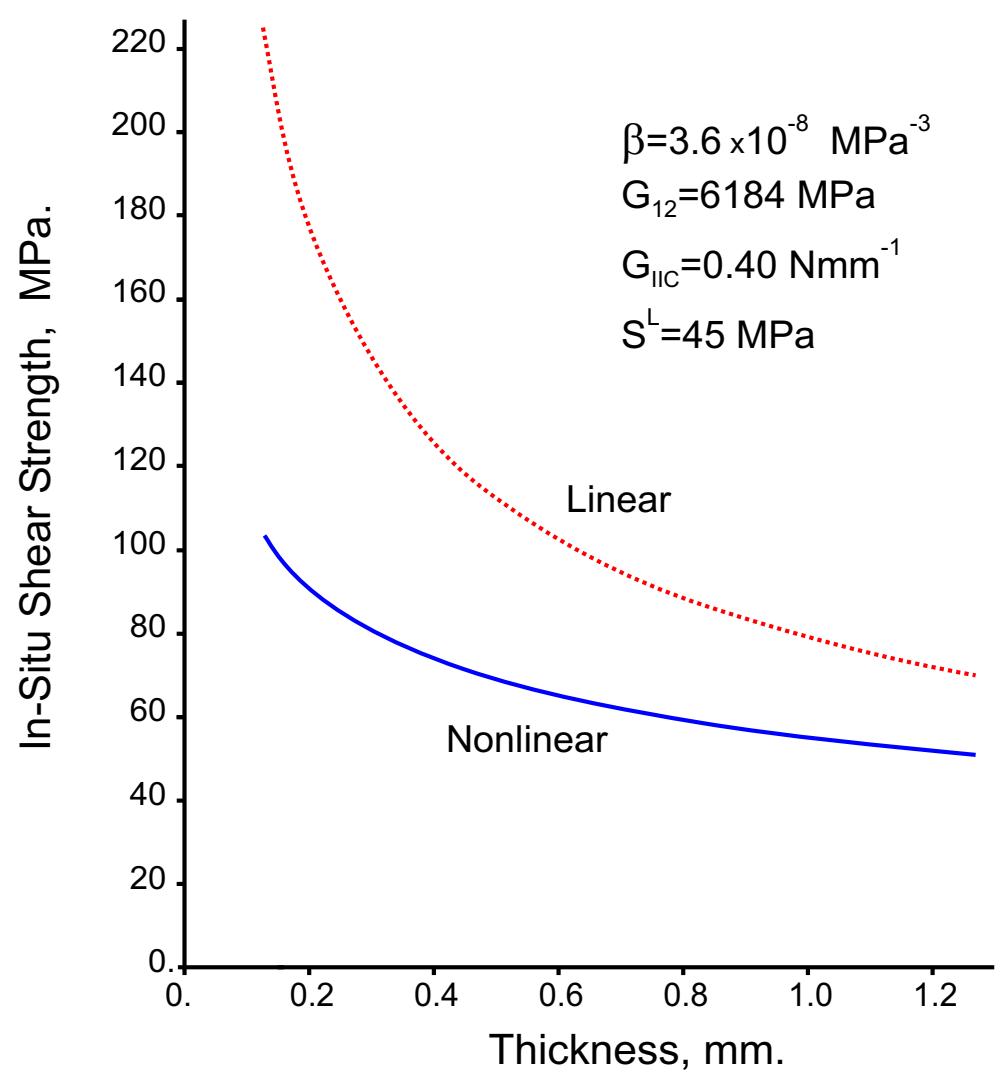

Fig. 8. Linear and non-linear predictions for the in-situ shear strength of a thin embedded ply. 


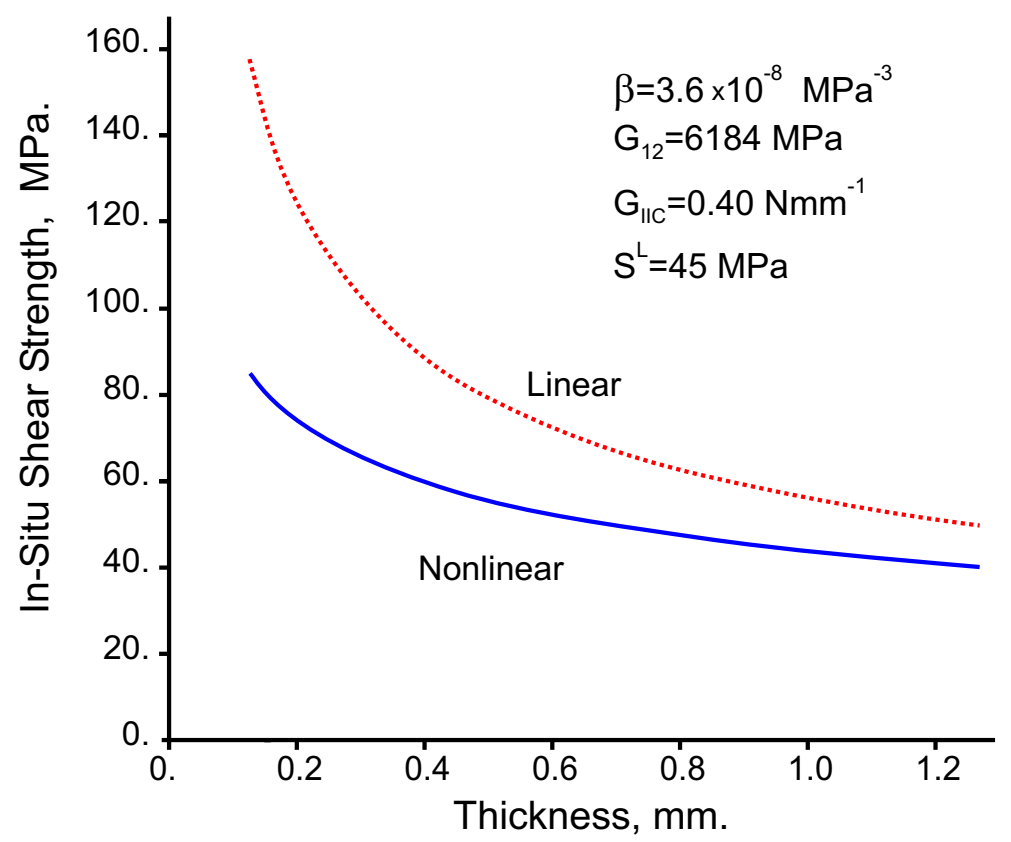

Fig. 9. Linear and non-linear predictions for the in-situ shear strength of a thin surface ply.

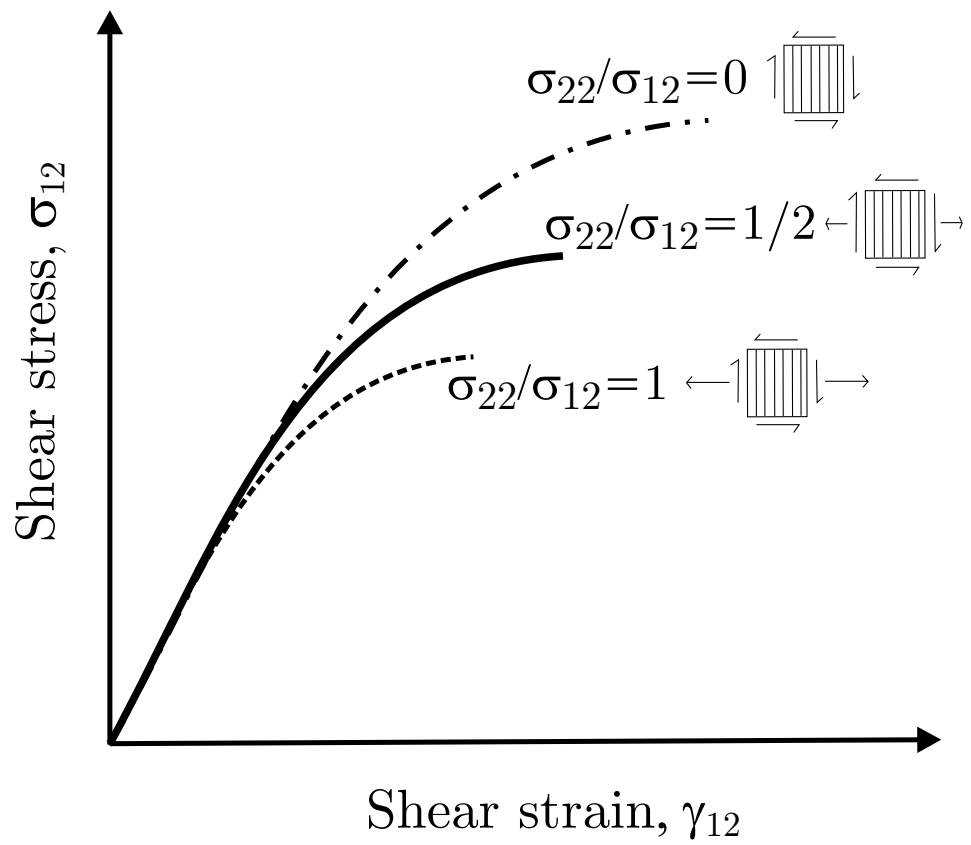

Fig. 10. Effect of transverse normal stress in the shear stress-shear strain relation (after Puck [26]). 


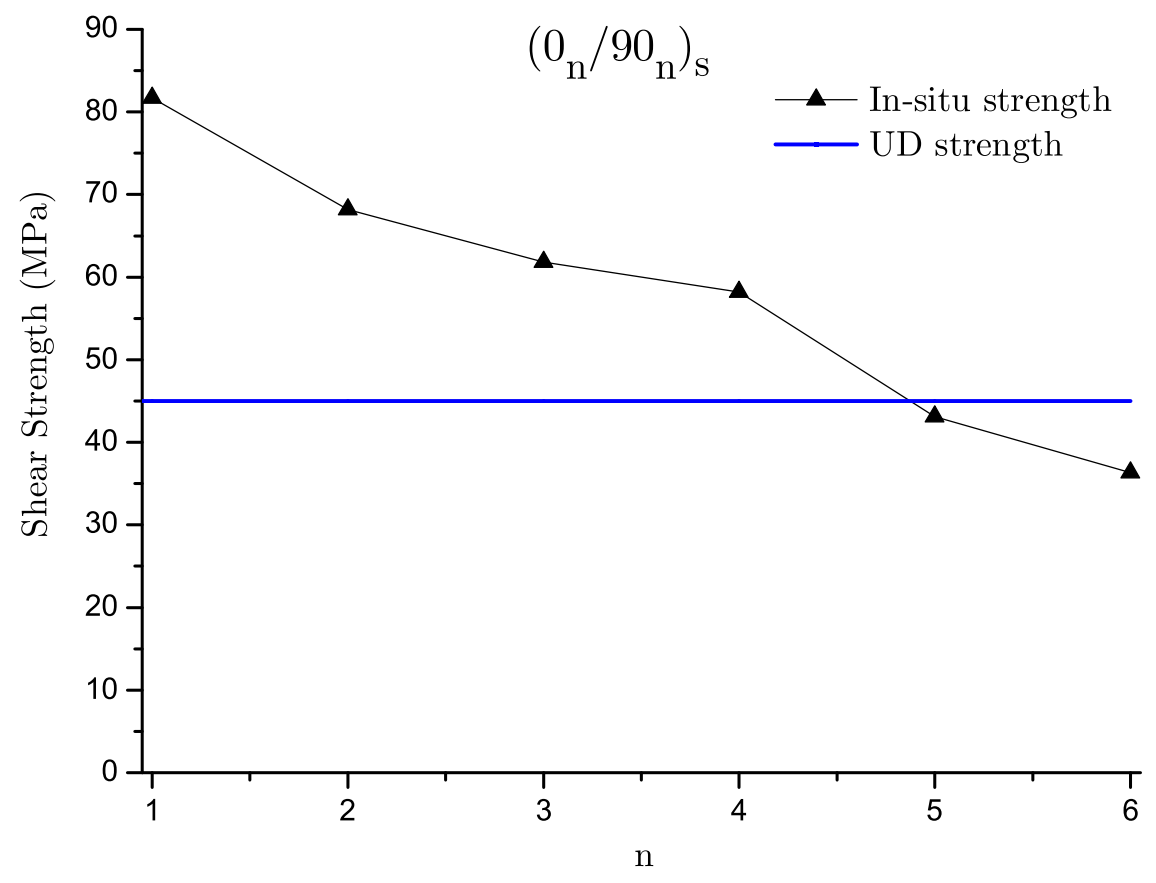

Fig. 11. Experimental results: in-situ and unidirectional shear strengths.

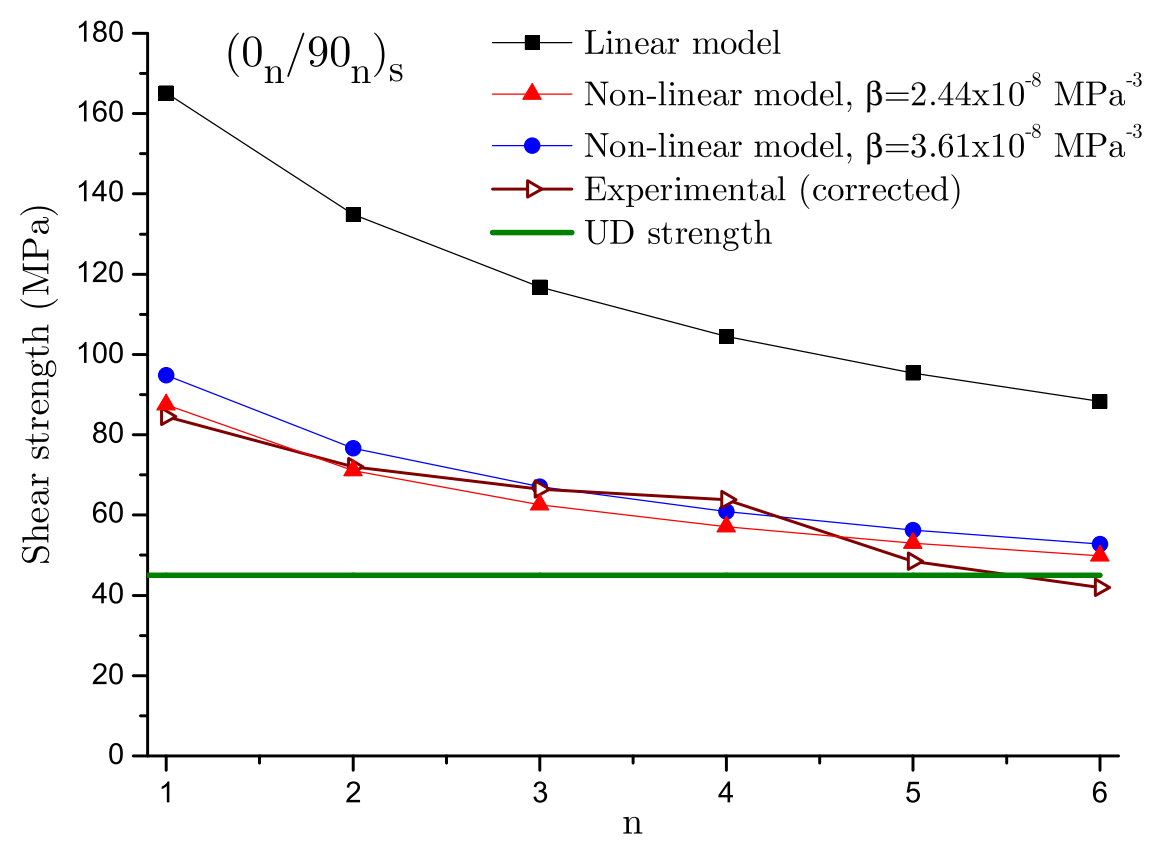

Fig. 12. Comparison between model predictions and experimental data. 


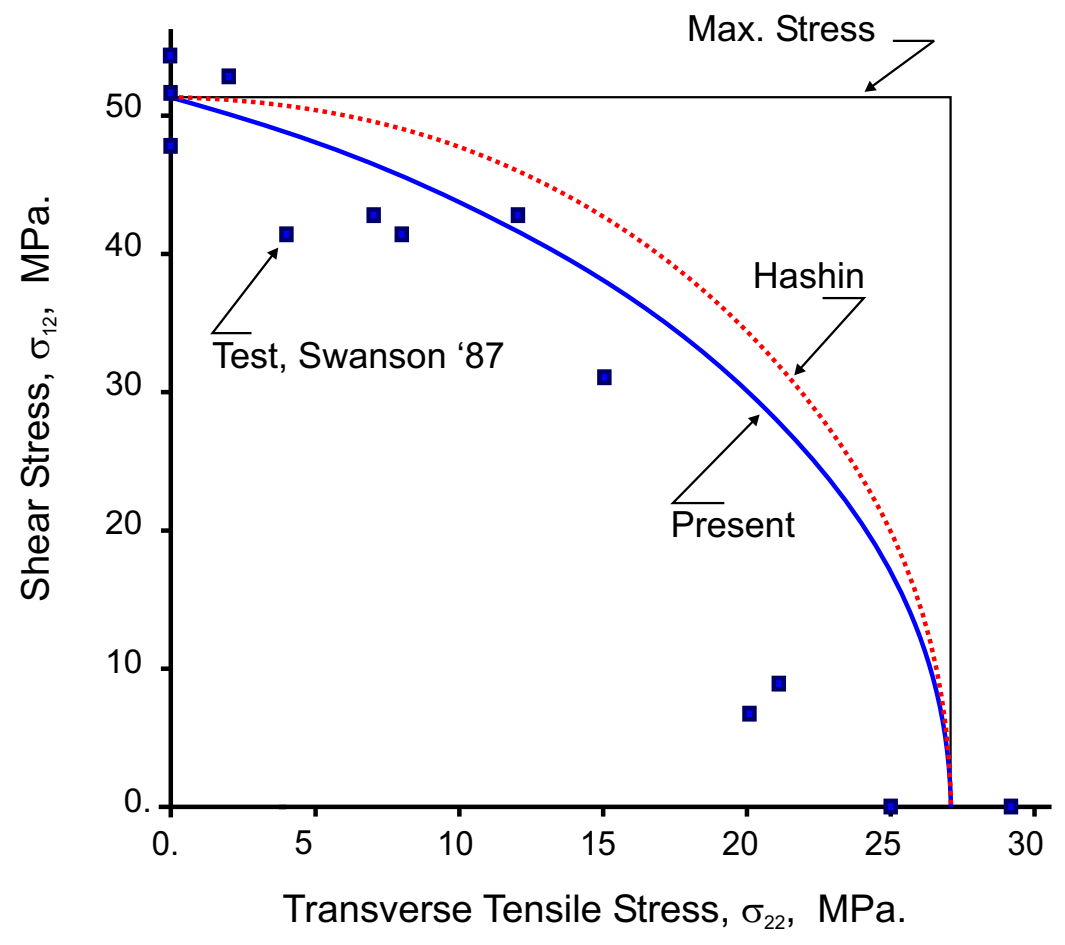

Fig. 13. Comparison between model predictions and experimental data- AS4-55A.

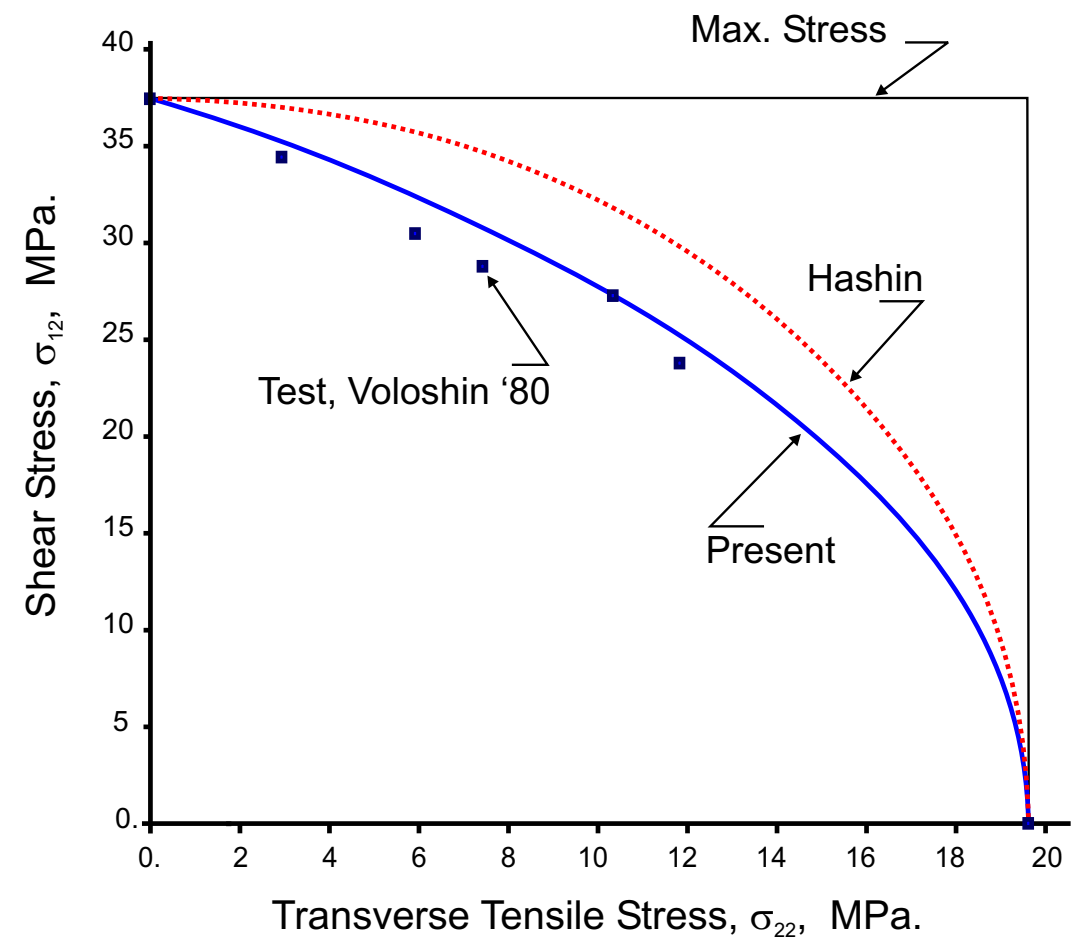

Fig. 14. Comparison between model predictions and experimental data-Scotch-Ply. 


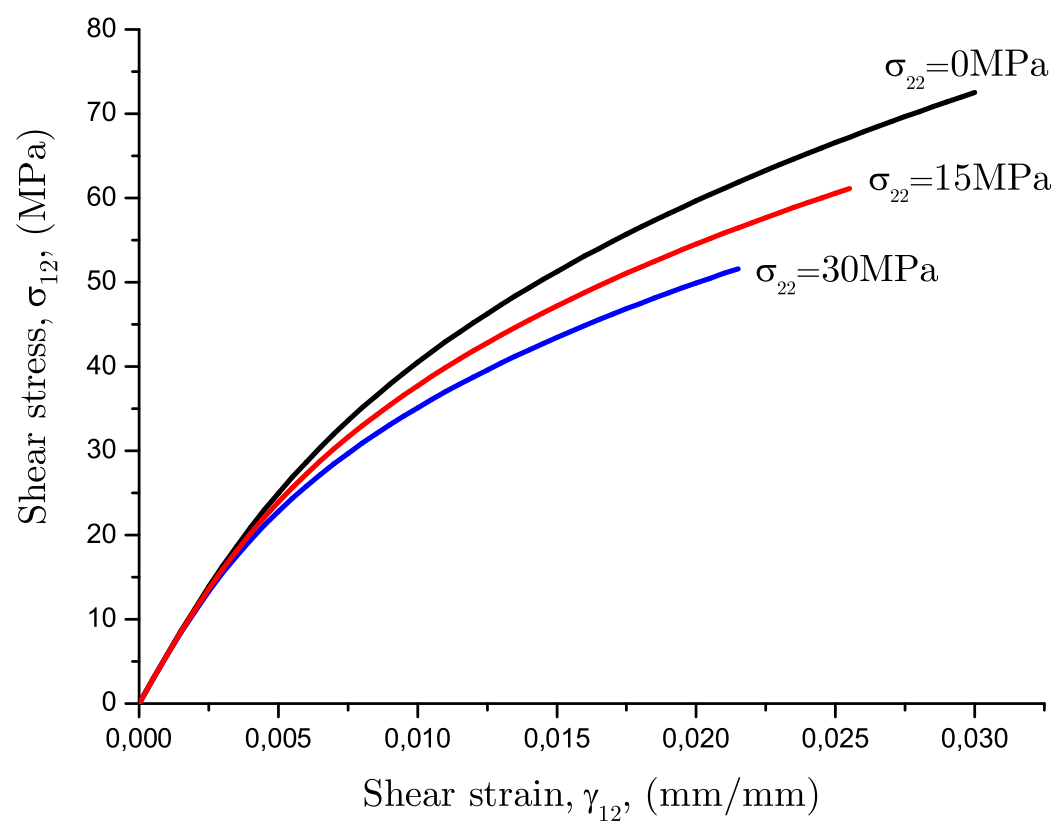

Fig. 15. Shear stress-shear strain relations for $\beta=\beta\left(\sigma_{22}\right)$.

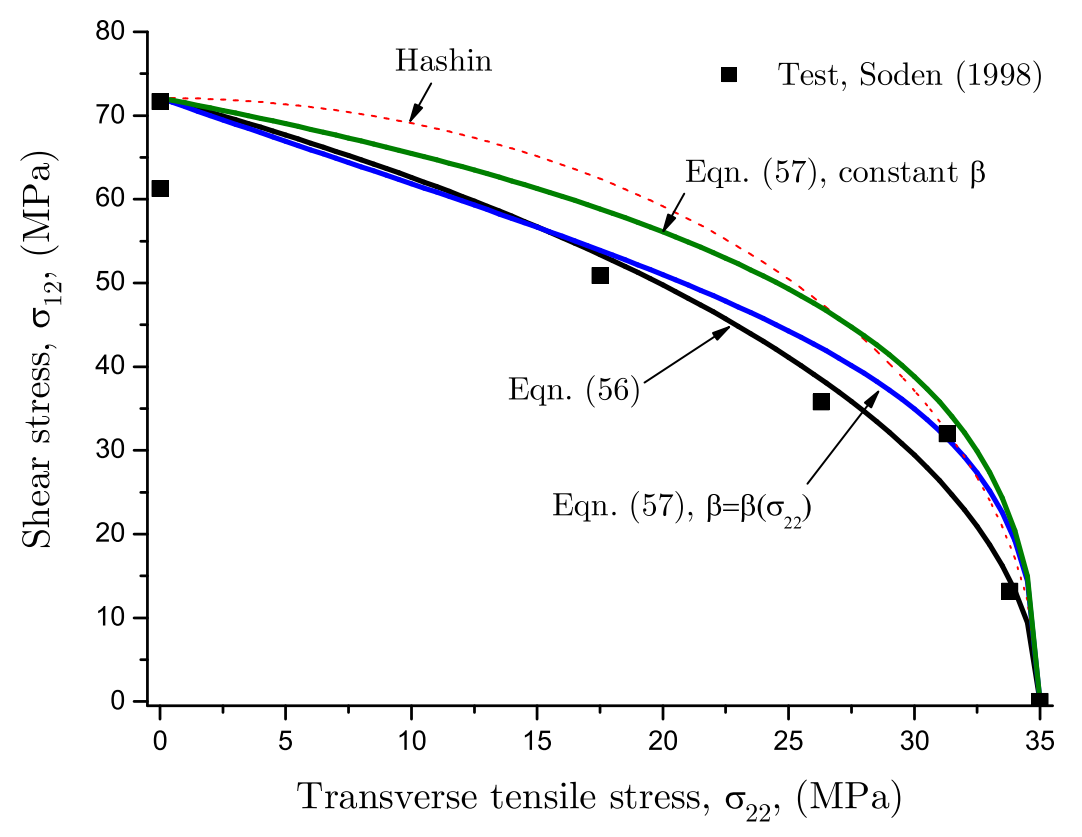

Fig. 16. Comparison between model predictions and experimental data-EGlass-LY556. 


\section{Tables}

Table 1

T300/1034-C elastic properties.

\begin{tabular}{lllll}
\hline \hline $\mathrm{E}_{1}(\mathrm{GPa})$ & $\mathrm{E}_{2}(\mathrm{GPa})$ & $\mathrm{G}_{12}(\mathrm{GPa})$ & $\mathrm{S}_{\mathrm{L}}(\mathrm{MPa})$ & $\nu_{12}$ \\
\hline 168.2 & 12.5 & 6.2 & 45.0 & 0.3 \\
\hline \hline
\end{tabular}

Table 2

T300/1034-C properties.

\begin{tabular}{lll}
\hline \hline $\mathrm{G}_{\text {Ic }}\left(\mathrm{Nmm}^{-1}\right)$ & $\mathrm{G}_{\text {IIc }}\left(\mathrm{Nmm}^{-1}\right)$ & $\mathrm{t}(\mathrm{mm})$ \\
\hline 0.228 & 0.455 & 0.127 \\
\hline \hline
\end{tabular}

Table 3

Shear nonlinearity parameter $\beta$ for two CFRP material systems.

\begin{tabular}{ll} 
Material & $\beta \times 10^{-8}\left(\mathrm{MPa}^{-3}\right)$ \\
\hline T300/976 & 2.44 \\
T300/BSL 914C & 3.61 \\
\hline \hline
\end{tabular}

Table 4

Elastic properties and strengths.

\begin{tabular}{lllllll}
\hline \hline Material & $\mathrm{E}_{1}(\mathrm{GPa})$ & $\mathrm{E}_{2}(\mathrm{GPa})$ & $\mathrm{G}_{12}(\mathrm{GPa})$ & $\nu_{12}$ & $\mathrm{Y}^{\mathrm{T}}(\mathrm{MPa})$ & $\mathrm{S}^{\mathrm{L}}(\mathrm{MPa})$ \\
\hline Scotch-Ply & 53.5 & 17.0 & 5.8 & 0.3 & 19.6 & 37.5 \\
E-Glass LY & 53.5 & 17.7 & 5.8 & 0.3 & 35.0 & 72.1 \\
AS4-55A & 126.0 & 11.0 & 6.6 & 0.3 & 27.0 & 51.3 \\
\hline \hline
\end{tabular}

